\title{
The treatment landscape in thyroid cancer: a focus on cabozantinib
}

\author{
This article was published in the following Dove Press journal: \\ Cancer Management and Research \\ 19 August 2015 \\ Number of times this article has been viewed
}

\section{Steven P Weitzman \\ Maria E Cabanillas \\ Department of Endocrine Neoplasia and Hormonal Disorders, The University of Texas MD Anderson Cancer Center, Houston, TX, USA}

Correspondence: Maria E Cabanillas Department of Endocrine Neoplasia and Hormonal Disorders, The University of Texas MD Anderson Cancer Center, I5 I5 Holcombe Blvd, Unit I46I, Houston, TX 77030, USA

Tel + I 7|3792 284|

Email mcabani@mdanderson.org

\begin{abstract}
Although patients with thyroid cancer generally fare well, there is a subset for which this is not necessarily true. Progress in understanding the molecular aberrations in thyroid cancer has led to a change in the management of these cases. Since 2011, four multikinase inhibitors (MKIs) have been approved by the US Food and Drug Administration for thyroid cancer cabozantinib and vandetanib for medullary thyroid cancer and sorafenib and lenvatinib for differentiated thyroid cancer. This change in the treatment landscape has raised challenges for practitioners who may not be familiar with the use of MKIs or with the treatment and natural history of advanced thyroid cancer in general. This article reviews the epidemiology, molecular drivers, and initial treatment of patients with thyroid cancer and offers practical guidance to assist with the determination of when to appropriately start an MKI. As an example, cabozantinib and its efficacy are discussed in detail. Close monitoring is required for all patients on targeted agents to assess for adverse effects and response to therapy. An approach to managing drug-related adverse events is detailed. Since these drugs are not curative and have not yet proven to prolong overall survival, it is critical to weigh the risks and benefits of treatment at every visit. The potential value of changing to a different agent following failure of an MKI is also addressed.
\end{abstract}

Keywords: chemotherapy, adverse event, targeted therapy, kinase inhibitor, VEGF, RET

\section{Introduction}

More than a decade ago, the first drugs that target specific molecular aberrations in cancer entered the market. Over the years, this concept has been applied to several different targets for many types of cancer. The identification of molecular targets relevant to thyroid cancer has led to significant gains in the treatment of patients with advanced thyroid cancer, including approval by the US Food and Drug Administration (FDA) of four targeted multikinase inhibitors (MKIs) - cabozantinib and vandetanib for medullary thyroid cancer (MTC) and sorafenib and lenvatinib for differentiated thyroid cancer (DTC). The molecular pathways relevant to thyroid cancer as well as potential drugs to target those pathways have been fertile areas of investigation. This review discusses the current knowledge of these molecular alterations, with a focus on the use of cabozantinib in patients with thyroid cancer.

Cabozantinib (XL184) is an MKI developed by Exelixis, Inc. (San Francisco). The chemical name of cabozantinib $(S)$-malate is $N$-(4-(6,7-dimethoxyquinolin4-yloxy)phenyl)- $N^{\prime}$-(4-fluorophenyl)cyclopropane-1,1-dicarboxamide, $(2 S)$ hydroxybutanedioate. ${ }^{1}$ This agent became a focus of interest in thyroid cancer when it was found to inhibit many of the kinases that play a role in this cancer. The data regarding 
its efficacy in the treatment of thyroid cancer are discussed along with practical guidance concerning its clinical use.

\section{Epidemiology of thyroid cancer}

Thyroid cancer is the most common endocrine malignancy and was the ninth most frequently diagnosed cancer in the USA in 2014. According to the US Surveillance, Epidemiology, and End Results (SEER) Program, there were an estimated 62,980 new cases of thyroid cancer in the USA in 2014. Furthermore, the estimated prevalence of thyroid cancer in the USA was 566,708 in 2011. Over time, there has been an increase in incidence of $5.5 \%$ each year, and death rates have risen at a rate of $0.8 \%$ each year. ${ }^{2}$

Fortunately, SEER data indicate that $68 \%$ of patients have localized disease at diagnosis, and these patients have a 5 -year survival rate of $99.9 \%$. Another $26 \%$ of patients have regional spread, and $4 \%$ have distant spread at diagnosis. Approximately, $9 \%$ of patients with DTC will be found to have distant metastases during their lifetime. ${ }^{3}$ For those with anaplastic thyroid cancer (ATC), more than $90 \%$ will develop metastatic disease. ${ }^{4}$ Even though the survival rate for early-stage disease is excellent, the same cannot be said for advanced-stage disease. The estimated number of deaths due to thyroid cancer in the USA was 1,890 in 2014, and the 5-year survival rate for those with distant disease at diagnosis is only $54.7 \%{ }^{2}$

Thyroid cancers are grouped into three categories: MTC, DTC, and ATC. Papillary thyroid cancer (PTC), follicular thyroid cancer (FTC), and poorly differentiated thyroid cancer (PDTC) subtypes are included in the DTC category. According to SEER, the types of thyroid cancer diagnosed between 1992 and 2006 were PTC in $83.8 \%$, FTC in $10.4 \%$, MTC in $2.2 \%$, ATC in $1.3 \%$, and other/unspecified in $2.2 \%{ }^{5}$ Although they all originate in the thyroid gland, they represent different tumors with different biology and molecular alterations.

\section{Pathogenesis of thyroid cancer}

MTC is derived from the parafollicular C-cells and is a manifestation of a genetic syndrome in approximately one-quarter of patients. The three genetic syndromes with which MTC is known to be associated are multiple endocrine neoplasia $2 \mathrm{~A}$, multiple endocrine neoplasia 2B, and familial MTC. In these syndromes, there is an almost universal gain-of-function mutation in the transmembrane tyrosine kinase RET (REarranged during Transfection), which is inherited in an autosomal dominant fashion. For these patients, there is a known relationship between the genotype and the aggressiveness of the phenotype. In sporadic cases of MTC, the majority harbor a somatic RET mutation. On the other hand, up to $25 \%$ of these patients have no mutation in $R E T .{ }^{6} \mathrm{Of}$ the $R E T$-negative cases, it has been noted that $68 \%$ have a mutation in $R A S{ }^{7}$ Furthermore, vascular endothelial growth factor (VEGF) is known to be an important kinase in MTC. ${ }^{8}$

The remaining types of thyroid cancer are derived from thyroid follicular cells. The Cancer Genome Atlas (TCGA) performed detailed analyses of the somatic changes seen in PTC, the most common form of thyroid cancer, and their analysis of 496 PTCs describes several of the classic genetic alterations in these tumors. Among these drivers are mutations in BRAF (59.7\%), NRAS (8.5\%), HRAS (3.5\%), and $K R A S(1 \%)$. RET fusions were identified in $6.8 \%$ and found to be mutually exclusive with $B R A F$ and $R A S$ mutations. Several drivers that had not yet been described were also identified. These include alterations in genes such as EIF1AX (eukaryotic translation initiation factor 1A, X-linked), PPM1D (protein phosphatase, $\mathrm{Mg}^{2+} / \mathrm{Mn}^{2+}$ dependent, 1D), and CHEK2 (checkpoint kinase 2). These discoveries have reduced the number of cases with no known driver mutation (ie, the "dark matter") from $25 \%$ to only $3.5 \%{ }^{9}$

Less is known about the molecular abnormalities underlying the other types of thyroid cancer. In FTC, there are activating mutations in $R A S$ in $45 \%$ of cases. Furthermore, there is a PAX8-PPARG fusion in $35 \%$ of FTCs. ${ }^{10}$ As in MTC, VEGF is an important angiogenic factor in DTC..$^{11,12}$

PDTC and ATC represent tumors that originate from follicular cells, but have varying degrees of loss of differentiation. PDTC has some loss of differentiation, while ATC has more extensive loss. These tumors can occur coincident with DTC, implicating progressive dedifferentiation as the etiology. As a result, many of the previously mentioned drivers may be seen in these entities as well. However, there are generally other mutations, which are thought to occur later, leading to loss of differentiation. Inactivation of the $p 53$ gene is a highly important step in the development of PDTC and ATC. The mutation rates seen in PDTC and ATC (respectively) are TP53 ( $20 \%$ vs $70 \%$ ), CTNNBI (20\% vs $65 \%$ ), RAS ( $35 \%$ vs $55 \%$ ), BRAF (15\% vs $20 \%)$, and PIK3CA (6\% vs $20 \%){ }^{10,13}$

\section{Initial management of thyroid cancer \\ Medullary thyroid cancer}

For patients with newly diagnosed MTC, the evaluation includes a minimum of checking tumor markers (calcitonin and carcinoembryonic antigen), a comprehensive ultrasound of the neck, and genetic testing for one of the familial MTC syndromes. Cross-sectional imaging may be obtained if needed for surgical planning or if distant metastases are 
suspected. Furthermore, if there is a known germline $R E T$ mutation (or an unknown mutation status), then biochemical workup to rule out primary hyperparathyroidism and pheochromocytoma is warranted. Once this is completed, a total thyroidectomy with central neck dissection is generally recommended. More extensive surgery may be needed for some patients, if indicated by their preoperative evaluation. If the patient is considered to have a high risk of recurrence, external beam radiation therapy may improve locoregional control. ${ }^{14}$ A detailed discussion of the appropriate use of external beam radiation therapy in thyroid cancer is beyond the scope of this review. Since the response to initial treatment impacts survival and the risk of recurrence, an experienced multidisciplinary team should be involved from the beginning. ${ }^{15}$ The American Thyroid Association (ATA) guidelines for the management of MTC were updated in 2015 and address many of these issues. ${ }^{16}$

\section{Differentiated thyroid cancer}

For patients with newly diagnosed DTC, the preoperative evaluation is a comprehensive neck ultrasound. ${ }^{17}$ Crosssectional imaging may be obtained if needed for surgical planning or if distant disease is suspected. The extent of surgery depends upon the results of preoperative imaging along with cytological examination of the fine needle aspirate. The surgical procedure may range from hemithyroidectomy to total thyroidectomy with comprehensive neck dissection. Following surgery, thyroid-stimulating hormone (TSH)suppressive therapy with high-dose thyroid hormone is usually the standard. The degree of TSH suppression is based upon the potential for residual disease and the estimated risk for recurrent disease/death. ${ }^{18}$ Additionally, radioiodine (RAI) may be considered for remnant ablation, adjuvant therapy, or treatment of distant metastases if it is RAI-avid. However, the decision to treat (and the dose chosen) should be individualized. The most recent version of the ATA guidelines for the management of DTC discusses the initial management of DTC, and an updated version is expected later this year. ${ }^{19}$

\section{Anaplastic thyroid cancer}

ATC is a rare type of thyroid cancer that is rapidly progressive and is associated with significant mortality. As a result, this disease should be treated as a medical emergency, prompting an expeditious initial evaluation by a multidisciplinary team experienced in ATC. This includes extensive imaging to determine resectability and stage, pathology review, and evaluation of airway and vocal cord function. If the disease can be resected with curative intent and acceptable. ${ }^{20}$ Otherwise, the next step is consideration of palliative radiation (with or without concurrent radiosensitizing chemotherapy). ${ }^{21}$ The chemotherapy agents that are often used concurrently with radiation for radiosensitization include platinum-, taxane-, and anthracycline-based regimens. ${ }^{22}$ Traditional cytotoxic chemotherapy can also be considered for treatment of distant disease, but participation in clinical trials is highly recommended because response rates are low. ${ }^{23}$ The initial management of ATC is detailed in the ATA guidelines for the management of ATC. ${ }^{22}$

\section{Management of residual, recurrent, and distant disease in MTC and DTC}

Options for the management of asymptomatic residual, recurrent, and distant metastatic disease in MTC and DTC include watchful waiting, surgery, radiotherapy, cryoablation, and chemoembolization. ${ }^{18}$ Unlike patients with MTC and ATC, those with DTC who have residual, recurrent, or distant metastatic disease may benefit from TSH suppression and RAI (depending upon the disease burden and iodine avidity of the tumors). DTC is considered RAI-refractory if known disease does not take up iodine on a diagnostic or posttreatment scan, if the tumor grows despite RAI treatment, or if the patient has received a cumulative dose of $\geq 600$ $\mathrm{mCi}$ of I-131. ${ }^{24} \mathrm{RAI}$ is not an option for tumors known to be RAI-refractory.

For DTC patients with skeletal metastases, zoledronic acid has shown efficacy in reducing the number of skeletalrelated events. ${ }^{25}$ As an alternative, a receptor activator of nuclear factor kappa-B ligand (RANKL) inhibitor (eg, denosumab) can be considered in these patients. In MTC patients, a RANKL inhibitor or intravenous bisphosphonate is sometimes used with the intent of reducing skeletal-related events, even though they have not yet been definitively established as effective in MTC. ${ }^{18}$

\section{Cabozantinib}

Since cabozantinib targets many of the alterations seen in thyroid cancer (Figure 1), it was considered as a promising agent for the treatment of advanced thyroid cancer when it was introduced. ${ }^{26-28}$ Most notably, it strongly inhibits VEGFR-2, MET, and RET. Strong inhibition of RET made cabozantinib a particularly attractive candidate for use in patients with MTC. Other kinases inhibited by cabozantinib include KIT, AXL, TIE2, and FLT3. Unlike vandetanib, cabozantinib does not significantly inhibit EGFR. ${ }^{29}$ 


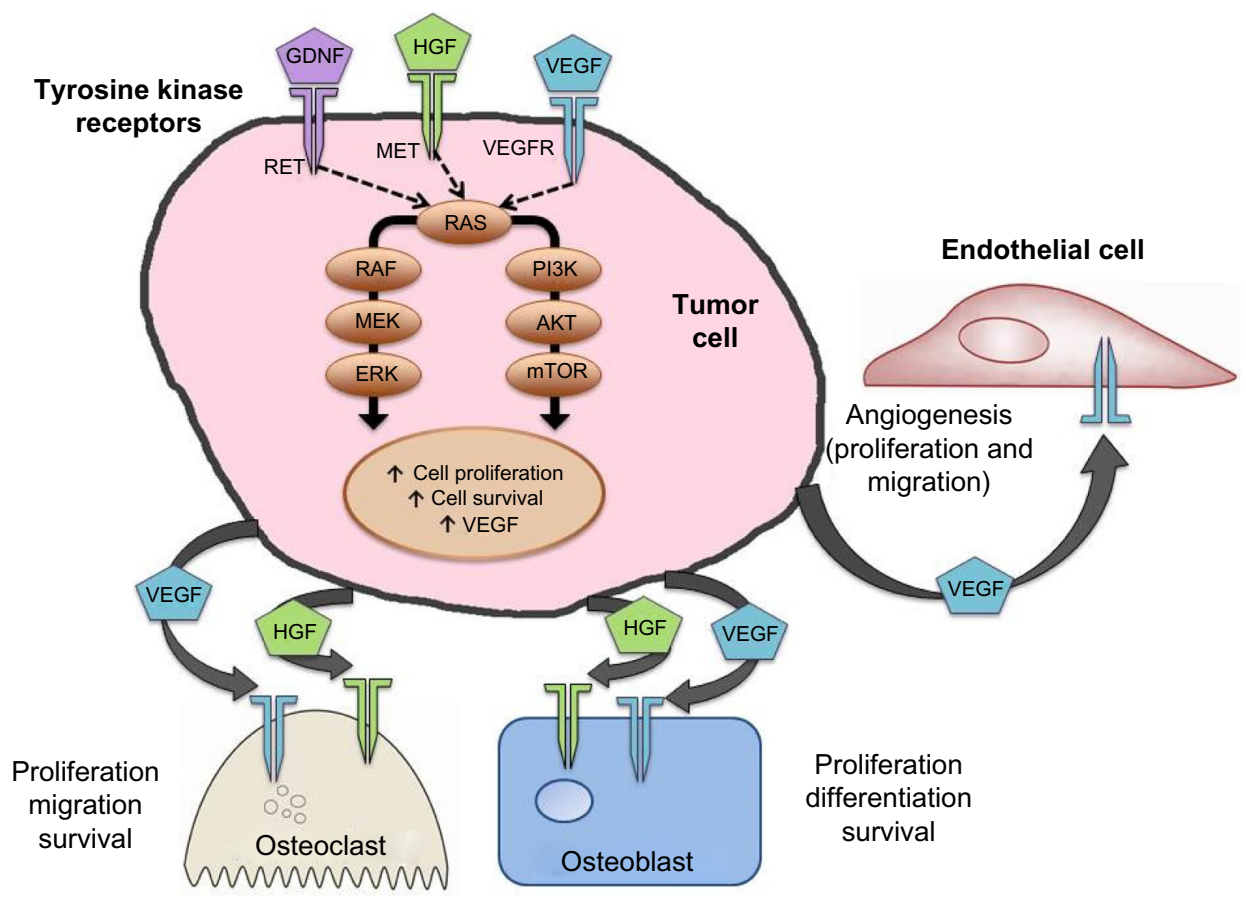

Figure I Molecular pathways important in MTC and targets relevant to cabozantinib.

Notes: Mutations in RET are the most common drivers of MTC; however, there are other important kinases which are upregulated and are targeted by cabozantinib. For example, cabozantinib is a potent inhibitor of MET and VEGFR2. MET and VEGFR cooperate to drive tumor angiogenesis, invasion, and metastasis. Upregulation of MET is associated with the ability of tumors to evade antiangiogenic treatment. Furthermore, osteoblasts and osteoclasts express MET and VEGF receptors. Hepatocyte growth factor, the only known ligand for the MET receptor, may be an important factor directing cross talk between tumor cells and osteoblasts/osteoclasts. Thus, simultaneous inhibition of MET and VEGF receptors may block progression of osteolytic and osteoblastic bone metastases.

Abbreviations: MTC, medullary thyroid cancer; RET, rearranged during transfection; VEGF, vascular endothelial growth factor; VEGFR, vascular endothelial growth factor receptor.

The inhibitory activity of cabozantinib, along with several other MKIs, is summarized in Table $1 . .^{29-40}$

\section{Clinical trials with cabozantinib and other MKIs in advanced thyroid cancer}

The earliest cabozantinib clinical trial that included thyroid cancer patients was a Phase I dose-escalation study carried out in 85 patients with solid tumors. An expansion phase included 37 patients with MTC. The results showed that the peak plasma levels and the area under the curve for the plasma concentration-time curve are dose dependent. A steady state was reached at 15 days, and the terminal half-life with daily dosing was 91.3 hours. Pharmacokinetic results were the same in the patients with MTC as in the remainder of the cohort. The adverse events (AEs), tumor marker responses, and radiographic tumor responses were assessed as well. Cabozantinib had a side effect profile comparable to those of other MKIs, and the results indicated that cabozantinib may lead to radiographic responses in patients with MTC. ${ }^{41}$ These results led to initiation of a Phase III trial in MTC.

An international, double-blind, placebo-controlled Phase III trial in patients with metastatic MTC who had radiographic progression of disease within the 14 months before entry led to the US regulatory approval of cabozantinib in this disease. The 330 patients with progressive disease were

Table I IC S0 $(\mathrm{nM})$ for commercially available multikinase inhibitors studied in thyroid cancer

\begin{tabular}{llllllllll}
\hline & RET & RET/PTC3 & VEGFR-I & VEGFR-2 & VEGFR-3 & c-Met & EGFR & FGFR2 & BRAF V \\
\hline Cabozantinib $^{29}$ & 5.2 & & 12.2 & 0.035 & 6 & c-Kit \\
Lenvatinib $^{30}$ & 6.4 & & 4.7 & 3 & 2.3 & $1.3-14.6$ & & & \\
Pazopanib $^{31}$ & & & 10 & 30 & 47 & & & \\
Sorafenib $^{32-35}$ & 5.9 & 50 & 26 & 90 & 20 & & & \\
Sunitinib $^{36-38}$ & & 224 & 2 & 9 & 17 & & & \\
Vandetanib $^{39,40}$ & & 100 & 1,600 & 40 & 110 & & 500 & & \\
\hline
\end{tabular}

Abbreviations: BRAF, v-raf murine sarcoma viral oncogenes homolog BI; EGFR, epidermal growth factor receptor; FGFR, fibroblast growth factor receptor; IC ${ }_{50}$, median inhibitory concentration; PTC, papillary thyroid carcinomas; RET, rearranged during transfection; VEGFR, vascular endothelial growth factor receptor. 
randomized 2:1 to receive either cabozantinib or placebo. The study group received cabozantinib $140 \mathrm{mg}$ daily, but was permitted drug holds and up to two dose reductions. The drug was continued until there was radiographic progression or intolerance requiring drug discontinuation. Notably, patients from the placebo group were not allowed to cross over. The results showed a statistically significant increase in the median progression-free survival (PFS) to 11.2 months for those on cabozantinib versus 4.0 months for those on placebo (hazard ratio 0.28). An interim analysis showed no difference in overall survival (OS). The final analysis of OS did not show a statistically significant difference except in those with a germ line or somatic RET M918T mutation. Those who were positive for this mutation had an overall survival of 44.3 months on cabozantinib versus 18.9 months on placebo (hazard ratio 0.60). ${ }^{42}$ Dose reductions were required in $79 \%$ of patients. ${ }^{43}$ Cabozantinib was approved by the FDA on November 29, 2012, for patients with progressive, metastatic MTC. ${ }^{44}$

Vandetanib was approved in 2011.45 This approval was based on a Phase III trial of vandetanib, which randomized 331 patients with advanced MTC to receive vandetanib or placebo in a 2:1 ratio. The results showed a significant improvement in the median PFS in those who received vandetanib (estimated 30.5 months) compared with those who received placebo (19.3 months), with a hazard ratio $0.46 .{ }^{46}$ There was no requirement for disease progression prior to enrollment in this trial, explaining the very long PFS in the placebo arm. Moreover, the placebo patients were allowed to cross over to open-label vandetanib.

Currently, two MKIs are approved by the FDA for patients with DTC. Sorafenib was approved in 2013, for the treatment of metastatic DTC. ${ }^{47}$ In the Phase III trial of sorafenib in patients with progressive, RAI-refractory, locally advanced or metastatic DTC, median PFS was prolonged to 10.8 months for the patients receiving sorafenib versus 5.8 months for the placebo group (hazard ratio 0.59). The objective response rate was $12.2 \%$ in the sorafenib arm and $0.5 \%$ in the placebo arm. ${ }^{48}$ Lenvatinib was subsequently approved in 2015 for patients with progressive, RAI-refractory DTC. ${ }^{49}$ In the Phase III trial of lenvatinib, there was a prolongation of PFS to 18.3 months in the treatment arm versus 3.6 months in the placebo group (hazard ratio, 0.21 ). The response rate was $64.8 \%$ in the treatment arm and $1.5 \%$ in the placebo arm. ${ }^{50}$

While cabozantinib is not currently approved by the FDA for use in patients with DTC, there is some literature to support its use in this population. A cabozantinib trial was conducted as part of a drug-drug interaction study. Since cabozantinib is a noncompetitive inhibitor of CYP2C8 and a weak competitive inhibitor of CYP3A $4,{ }^{1}$ this trial was designed to study the potential interaction between cabozantinib and rosiglitazone (a substrate of CYP2C8). The results showed no alteration in the single-dose pharmacokinetics of rosiglitazone in patients who were treated with daily cabozantinib. A secondary endpoint was to study the efficacy in DTC and renal cell carcinoma. This trial enrolled 15 DTC patients. Despite the fact that the majority of patients were heavily pretreated, 53\% had a partial response. ${ }^{51}$ The median OS and PFS were not reached. These promising results led to two Phase II studies to assess the response to cabozantinib as first-line and salvage therapy for DTC (NCT02041260, NCT01811212). ${ }^{52,53}$

There is very little information regarding the use of MKIs in patients with ATC and none for cabozantinib. Clinical trials with fosbretabulin, pazopanib, and sorafenib have not consistently shown benefit in patients with ATC. ${ }^{54-56}$ However, there were some promising data from a Phase II trial with lenvatinib in eleven patients with ATC. In this study, the patients with ATC had a median PFS of 7.4 months and a median OS of 10.6 months. ${ }^{57}$ In Japan, lenvatinib is approved for unresectable thyroid cancer, including ATC ${ }^{58}$ An ongoing clinical trial (NCT02034110) is looking at the combination of dabrafenib and trametinib in patients with $\mathrm{BRAF} \mathrm{V}^{600 \mathrm{E}}$-mutated rare cancers, including ATC. ${ }^{59}$ Another trial (NCT01236547) is recruiting patients with ATC to examine the potential benefit of adding pazopanib to paclitaxel in patients receiving intensity-modulated radiation therapy. ${ }^{60}$

Cabozantinib has been studied in prostate and renal cell cancers and is currently being studied in a number of solid tumors and hematologic malignancies (Table 2). ${ }^{61}$

\section{Selection of patients for targeted therapy}

The majority of thyroid cancer patients do not require systemic therapy. The decision to initiate treatment is based upon 1) failure of standard therapy, 2) the presence of disease that threatens vital structures, 3) symptomatic disease, and/ or 4) clinically significant disease with radiographic progression. ${ }^{18,62}$ The impact of side effects on quality of life must be taken into account since there has been no proven survival benefit. Multiple modalities are commonly employed in monitoring patients for progression. To objectively determine whether there has been radiographic progression, the response evaluation criteria in solid tumors (RECIST) guidelines are relied upon. ${ }^{63,64}$ The pace of disease progression can be used to help determine whether intervention is needed. 
Table 2 Ongoing clinical trials with cabozantinib in cancers other than thyroid cancer

\begin{tabular}{|c|c|c|c|c|}
\hline \multirow[t]{2}{*}{ Diagnoses } & \multicolumn{4}{|c|}{ ClinicalTrials.gov identifier and status } \\
\hline & Recruiting & $\begin{array}{l}\text { Active (not recruiting) } \\
\text { or not yet open }\end{array}$ & $\begin{array}{l}\text { Terminated or } \\
\text { suspended or completed }\end{array}$ & Unknown \\
\hline Astrocytic tumors & & & NCT0I068782 & \\
\hline Breast cancer & $\begin{array}{l}\text { NCT0226053I, } \\
\text { NCT0I44I947 }\end{array}$ & NCT0I738438 & & \\
\hline Colorectal cancer & NCT02008383 & & & \\
\hline Cholangiocarcinoma & & NCT0I954745 & & \\
\hline Endometrial cancer & NCT0I935934 & & & \\
\hline Gastrointestinal stromal tumor & & NCT022I6578 & & \\
\hline Glioblastoma & & & $\begin{array}{l}\text { NCT00960492, } \\
\text { NCT00704288 }\end{array}$ & \\
\hline Hepatocellular carcinoma & NCT0I908426 & & & \\
\hline Leukemia (acute myeloid) & NCT0I961765 & & & \\
\hline Lung carcinoma (non-small-cell) & NCT0I639508 & $\begin{array}{l}\text { NCTOI553656, } \\
\text { NCTOI } 708954, \\
\text { NCTOI } 866410, \\
\text { NCT02I } 32598\end{array}$ & NCT00596648 & \\
\hline Melanoma & & NCT0I709435 & NCT0I835I84 & \\
\hline Melanoma of the eye & & NCT0I835।45 & & \\
\hline Merkel cell carcinoma & NCT02036476 & & & \\
\hline Multiple myeloma & $\begin{array}{l}\text { NCT0I582295, } \\
\text { NCT0I866293 }\end{array}$ & & & \\
\hline Neurofibromas (plexiform) & NCT02101736 & & & \\
\hline Osteosarcoma or Ewing sarcoma & NCT02243605 & & & \\
\hline Ovarian, fallopian tube, or primary & & NCT0I7I67I5, & & \\
\hline peritoneal cavity cancer & & NCT023I5430 & & \\
\hline Pancreatic cancer & NCT0I 663272 & & & \\
\hline $\begin{array}{l}\text { Pancreatic neuroendocrine and } \\
\text { carcinoid tumors }\end{array}$ & & & & NCT0I466036 \\
\hline Pheochromocytoma (malignant) & NCT02302833 & & & \\
\hline Prostate cancer & $\begin{array}{l}\text { NCT0I83465I, } \\
\text { NCT0I } 630590 \text {, } \\
\text { NCT0I } 703065 \text {, } \\
\text { NCTOI } 8 I 2668 \text {, } \\
\text { NCTOI } 683994\end{array}$ & $\begin{array}{l}\text { NCTOI } 428219, \\
\text { NCTOI } 605227, \\
\text { NCTOI } 599793, \\
\text { NCTOI } 574937\end{array}$ & $\begin{array}{l}\text { NCTOI } 995058, \\
\text { NCTOI522443, } \\
\text { NCTOI } 347788\end{array}$ & \\
\hline Renal cell carcinoma & NCT0I835I58 & NCTOI865747 & & \\
\hline Sarcoma (soft tissue) & NCT0I755I95 & & & \\
\hline Sarcoma (uterine) & & NCT0I979393 & & \\
\hline Solid tumors (adult) & NCT0I822522 & NCT0I553656 & $\begin{array}{l}\text { NCT0I58882I, NCTOI835I84, } \\
\text { NCT00940225, NCTOI0I8745 }\end{array}$ & \\
\hline Solid tumors (childhood) & & NCT0I709435 & & \\
\hline Solid tumors or lymphoma & & & NCT002I5605 & \\
\hline Urothelial cancer & NCT0I688999 & & & \\
\hline
\end{tabular}

Our approach to patients with advanced thyroid cancer is elaborated in Figure 2. Although there are situations in which the need for targeted therapy seems clear, the patient's performance status must be assessed to determine if they are likely to tolerate targeted therapy. ${ }^{65}$ Since the kinase inhibitors are not considered curative, are employed as chronic therapies, and tend to fail over time, they are generally reserved for patients in whom other modalities have failed. If disease control can be achieved surgically, this is preferred.
In the case of DTC, the use of RAI should be considered for those whose tumor is RAI-avid. Any reasonable and feasible localized therapies, such as external beam radiotherapy, thermal ablation, or tumor embolization, should be undertaken if the disease is threatening vital structures (eg, spinal cord, brain), impairing mobility (eg, affecting the arm, leg, shoulder), or causing pain. It is important to remember that an elevated or rising tumor marker alone should not trigger systemic therapy. ${ }^{18}$ 


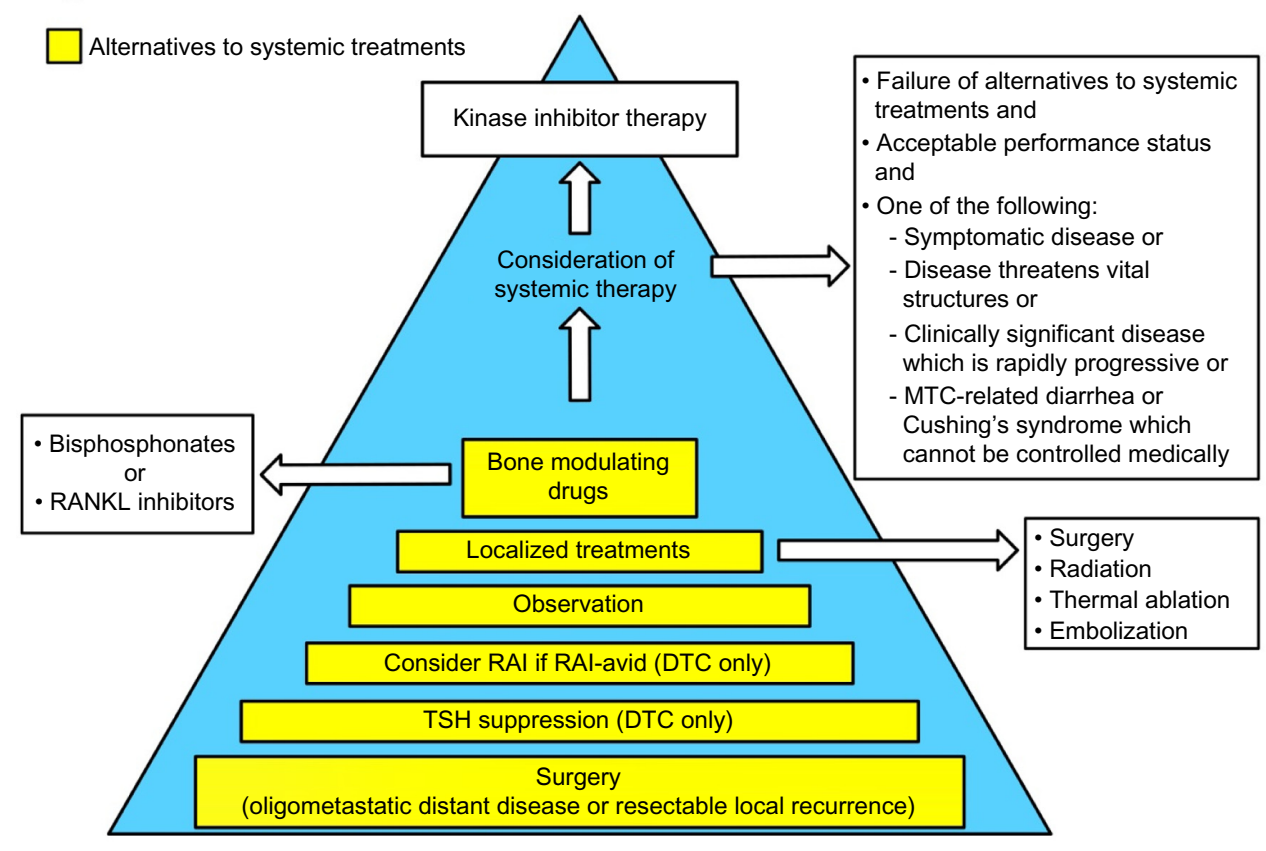

Figure 2 Management of locally advanced and/or metastatic differentiated MTCs and the criteria for initiation of kinase inhibitors.

Abbreviations: DTC, differentiated thyroid cancer; MTC, medullary thyroid cancer; RAI, radioiodine; RANKL, receptor activator of nuclear factor kappa-B ligand; TSH, thyroid-stimulating hormone.

\section{Choice of systemic therapy for thyroid cancer}

Given the potential for serious AEs, it is recommended that treatment with an MKI take place under the guidance of a physician who is experienced in the use of these drugs. Moreover, the support of a multidisciplinary team experienced in the management of such cases, is necessary to maximize patient safety. Unfortunately, there are currently no human trial data to indicate if there is a preferred sequence of drugs from an efficacy standpoint.

When choosing between the two approved drugs - cabozantinib and vandetanib - for progressive MTC, a patientcentered approach is recommended. The decision regarding which drug to start first is delineated in a 2014 paper by Cabanillas et al. ${ }^{66}$ The concept of using patient characteristics along with the differences in drug side effect profiles can be extended to other types of thyroid cancer. In addition to the drug's efficacy and potential side effects, the pace of progression, comorbid conditions, concurrent medications, prior procedures, and location of disease also must be taken into account (Figure 3) ${ }^{66}$ For example, the package insert for cabozantinib has a black box warning for gastrointestinal (GI) perforations and fistulas as well as hemorrhage. ${ }^{1}$ As a result, the risk factors for GI bleeding and fistula formation need to be addressed when assessing patients prior to starting targeted therapy. ${ }^{67-69}$ Important items in the medical history and review of systems include peptic ulcer disease, diverticulitis, and bleeding. Tumor invasion of the esophagus or trachea is thought to predispose to fistula formation (especially in a radiated field).

Another consideration is the presence of skeletal metastases, since cabozantinib may have some activity against certain types of bone lesions. In the Phase I trial of cabozantinib in patients with DTC, one patient who had received seven prior systemic therapies had a dramatic response in an osteoblastic calvarial metastasis. ${ }^{68}$ A Phase II trial in DTC is exploring the role of cabozantinib in skeletal metastases in this disease (NCT01811212).$^{53}$ It is notable that cabozantinib has been found effective in osteoblastic skeletal metastases of patients with prostate cancer. ${ }^{70}$

During the informed consent process, special attention should be paid to educate the patient regarding symptoms of rare but serious side effects. Reversible posterior leukoencephalopathy syndrome can present with headache, seizure, visual loss, or change in mental status. Osteonecrosis of the jaw has also been reported with cabozantinib. ${ }^{71}$ Therefore, a good oral and dental examination should be performed to assess risk, and patients should be warned to avoid invasive dental procedures. Since there have been wound complications in patients taking cabozantinib or 

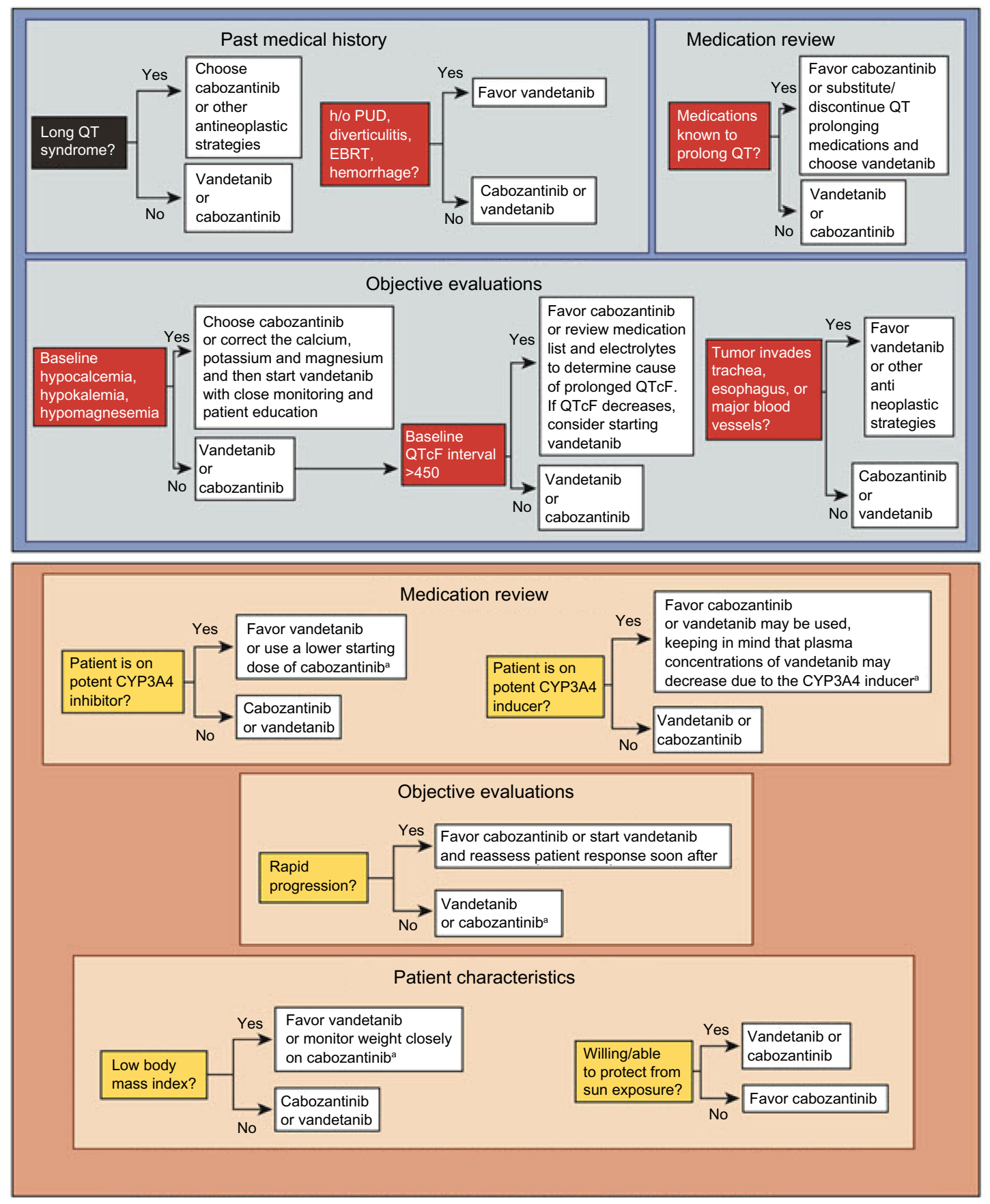

Figure 3 Factors in the choice of kinase inhibitor for patients with MTC.

Notes: Top panel: relative contraindications to consider when choosing vandetanib or cabozantinib for progressive or symptomatic MTC. For patients with MTC who qualify for systemic therapy, the patient's medical history, medications, electrocardiogram, and tumor characteristics should be reviewed carefully to determine which drug to start. Vandetanib should be avoided in patients who are at risk of prolonged QT interval as a result of their cardiac history, difficulty in managing hypocalcemia, or use of certain medications that cannot be substituted. Cabozantinib should be avoided in patients with a history of peptic ulcer disease, diverticulitis, or a tumor invading the trachea, esophagus, or major vessels because of the risk of perforation or fistula. In patients with these risk factors, vandetanib should be used with caution. Bottom panel: factors that may be taken into consideration when a patient has no relative contraindications to either vandetanib or cabozantinib (top panel). For such patients, a careful review of the medication list, tumor characteristics, and certain personal characteristics is important when selecting which drug to initiate. A list of CYP3A4 inhibitors and inducers can be found at http://www.medicine.iupui.edu/clinpharm/ddis/. Cabozantinib is the only drug proven to be effective in patients with progressive MTC; therefore, the rate of progression may be important when selecting which drug to initiate. Low body mass index and a patient's willingness to protect himself or herself from sun exposure are additional factors to be considered. Cabozantinib may cause weight loss, whereas vandetanib may cause weight gain. Photosensitivity is an adverse effect of vandetanib. ${ }^{a}$ Concomitant use of a CYP3A4 inhibitor drug may increase the plasma concentration of cabozantinib, resulting in toxicity, whereas CYP3A4 inducers may decrease the plasma concentration of vandetanib, resulting in decreased efficacy. Republished with permission from Cabanillas ME, Hu MI, Jimenez C. Medullary thyroid cancer in the era of tyrosine kinase inhibitors: to treat or not to treat - and with which drug - those are the questions.J Clin Endocrinol Metab. 20 I 4;99(I 2):4394. ${ }^{83}$ Copyright 20 I 4 by The Endocrine Society; permission conveyed through Copyright Clearance Center, Inc.

Abbreviations: EBRT, external beam radiation therapy; h/o, history of; MTC, medullary thyroid cancer; PUD, peptic ulcer disease; QTcF, rate-corrected QT interval using the Fridericia formula. 
another antiangiogenic drug, it is recommended that the drug be held prior to elective surgery and resumed once the wound has healed sufficiently. The package insert recommends stopping cabozantinib for 28 days prior to surgery. ${ }^{1}$

\section{Dosing of cabozantinib}

The FDA-approved starting dose for cabozantinib is $140 \mathrm{mg}$ daily; however, this dose can be difficult for patients to tolerate. As a result, starting doses of $100 \mathrm{mg}$ or lower may be advisable, with possible dose escalation if the drug is well tolerated. In the Phase II DTC trial (NCT01811212), cabozantinib was started at $60 \mathrm{mg}$ and escalated to $80 \mathrm{mg}$ if a partial response was not achieved. ${ }^{53}$ If necessary, the dose can be reduced in $20 \mathrm{mg}$ increments (capsules are available in 80 and $20 \mathrm{mg}$ ). ${ }^{1,66}$ Typically, the dose is not reduced below $40 \mathrm{mg}$ daily. Anecdotally, doses as low as $20 \mathrm{mg}$ daily have been used, but there are insufficient data to recommend this dose. Administration of cabozantinib while fasting is recommended.

\section{Management of AEs associated with cabozantinib and other MKIs Monitoring of AEs}

In addition to serial imaging and laboratory testing to assess the response to treatment, it is crucial to monitor patients receiving an MKI for the side effects that are commonly seen with these agents. AEs are ideally graded according to Common Terminology Criteria for Adverse Events (CTCAE) Version 4.0 at baseline and at each subsequent visit. The grades range from mild (grade 1) to fatal (grade 5). The US
National Cancer Institute has published a detailed description of the CTCAE system for grading individual AEs. ${ }^{72}$

An approach to monitoring patients with advanced thyroid cancer treated with an MKI was detailed by Carhill et $\mathrm{al}^{73}$ in 2013. Many AEs require supportive therapies (including additional medications), and some require drug holds and/or dose reductions. A current clinical trial (NCT01896479) is comparing two different cabozantinib doses (140 vs $60 \mathrm{mg}$ ) to assess if it is possible to achieve similar efficacy with fewer AEs in patients with MTC. ${ }^{74}$

It is important to remember that some AEs are serious and potentially fatal, although rare. Additionally, the cost of targeted therapies can be quite high and may exert a financial burden on patients and their families, which they may be reluctant to disclose. ${ }^{75}$

\section{Recommended management of AEs associated with cabozantinib and other MKIs}

In the Phase III trial of cabozantinib in patients with MTC, grade 3 (severe) or grade 4 (life-threatening) AEs occurred in $69 \%$ of those on cabozantinib and $33 \%$ of those on placebo. The most frequent AEs were diarrhea, hand-foot skin reaction (HFSR), decreased weight, decreased appetite, nausea, and fatigue. The most frequent AEs related to VEGF inhibition were hypertension, hemorrhage, and venous thrombosis. The most frequent blood chemistry abnormalities were increased aspartate aminotransferase, increased alanine aminotransferase, increased alkaline phosphatase, and hypocalcemia. Figure 4 demonstrates the frequency of the more common AEs. AEs that are rare but important

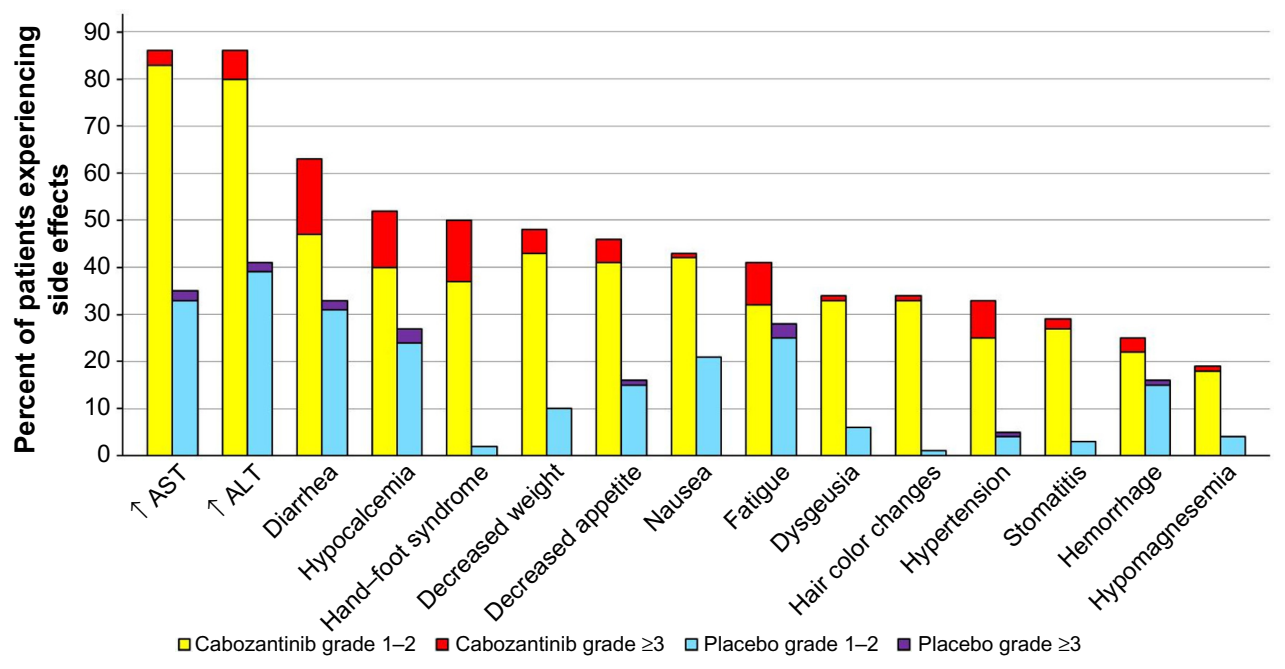

Figure 4 Most often observed nonhematologic adverse events in the Phase III trial of cabozantinib in patients with MTC. Abbreviations: ALT, alanine aminiotransferase; AST, aspartate aminotransferase; MTC, medullary thyroid cancer. 
include proteinuria, GI perforation, fistula formation, arterial thrombosis, wound complication, osteonecrosis, and reversible posterior leukoencephalopathy syndrome. ${ }^{43}$

Grade 1 AEs are mild and do not generally necessitate intervention. At the other end of the spectrum, grade 4 AEs generally require drug discontinuation. The management of grade 2 (moderate) and grade 3 (severe) AEs can be less straightforward. The intervention in these cases is based upon several factors. For grade 2 AEs, the key factors are whether the $\mathrm{AE}$ is amenable to supportive measures as well as the level of discomfort or distress experienced by the patient. The two notable exceptions are hypertension and proteinuria (Figure 5). Blood pressure needs to be aggressively managed to avoid the sequelae of uncontrolled hypertension. If the blood pressure is elevated, it is recommended that antihypertensive agents the patient is already taking be titrated to the maximum tolerated doses or that appropriate antihyper- tensive therapy be initiated. If the blood pressure remains uncontrolled, additional therapy should be started to achieve control. For most other grade 2 AEs, no change in therapy is needed if the AE is well tolerated by the patient and is easily managed with supportive measures. Clinical judgment should be used. However, if the AE is intolerable to the patient and not typically responsive to supportive measures, a drug hold and/or dose reduction may be needed.

For grade 3 AEs, a drug hold is generally necessary unless the AE can be swiftly managed with supportive measures. Once the AE has resolved, resumption of the drug at a lower dose can be considered. Continued intolerance after two dose reductions may be considered a reason to discontinue the drug. Although possible, moderate and severe hematologic AEs are not common in patients with thyroid cancer. ${ }^{76}$ Figure 5 outlines general recommendations for drug holds, dose reductions, and drug discontinuations.

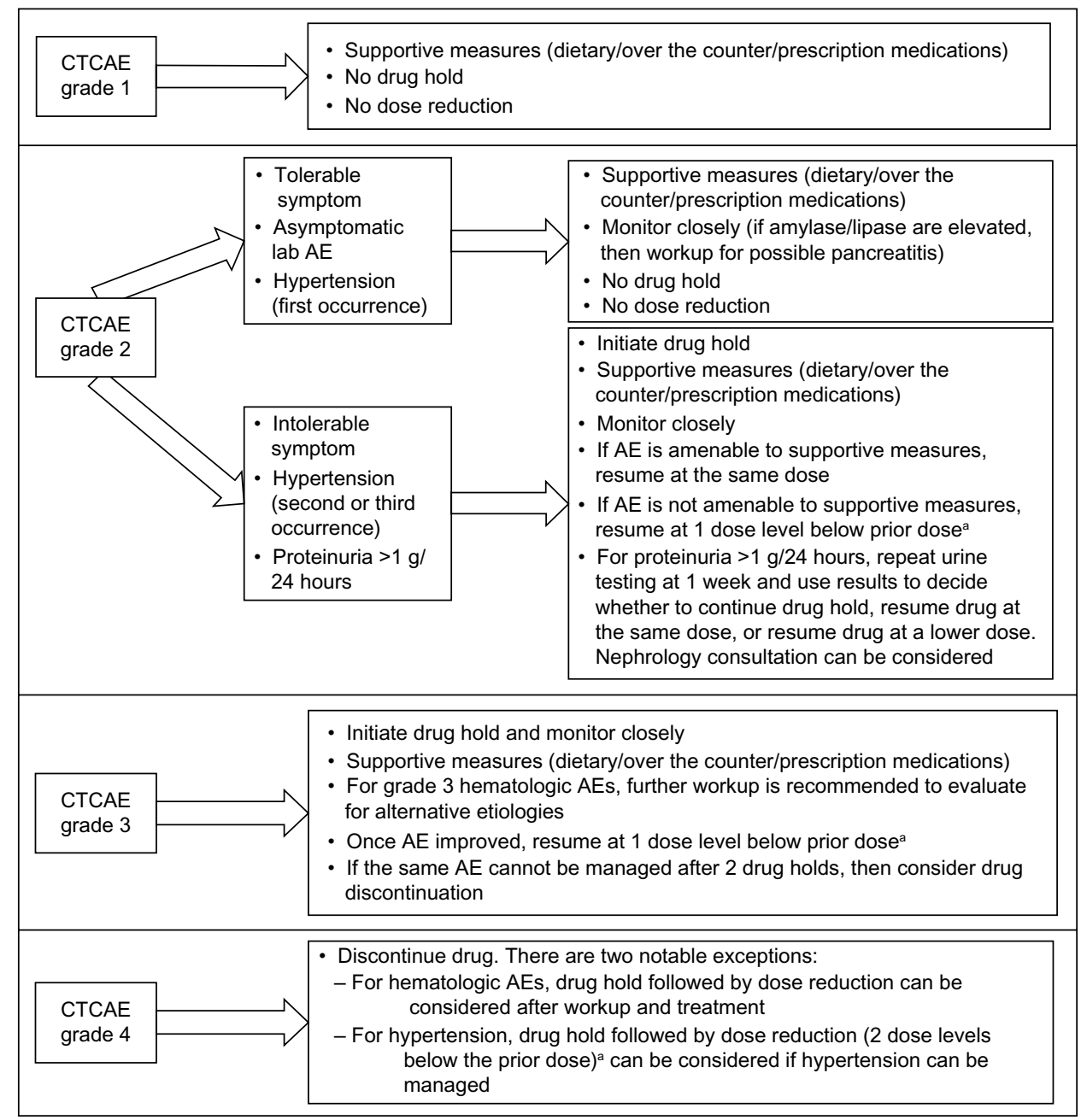

Figure 5 Suggested management of CTCAE AEs of kinase inhibitors.

Note: " "Dose level" generally refers to a reduction in the daily dose by $20 \mathrm{mg}$.

Abbreviations: AE, adverse event; CTCAE, common terminology criteria for adverse events. 
It is also important to closely monitor thyroid function tests to ensure that TSH remains within the desired range. It has been found that cabozantinib is associated with thyroid dysfunction in patients with sarcoma and bladder cancer. ${ }^{77}$ Although this may not be much of an issue in patients who are athyreotic, there has also been a report of an increase in TSH in patients with thyroid cancer after starting lenvatinib. ${ }^{78}$ As a result, attention must be paid to thyroid function tests with titration of the dose of thyroid hormone as needed.

\section{Treatment of common AEs associated with cabozantinib Hand-foot skin reaction}

HFSR is characterized by redness and swelling of the skin on the soles of the feet and the palms. Other features include pain, paresthesias, hyperkeratosis, or desquamation. The HFSR is most often seen in areas subject to pressure or friction (Figure 6). If not managed aggressively, it can affect a patient's ability to ambulate and even perform some activities of daily living. Patients should be advised that ill-fitting footwear will worsen this condition. Using a good moisturizer containing urea is important to keep the skin well hydrated and treat hyperkeratotic areas. If needed, a topical corticosteroid can be added. If the lesions are painful, topical or oral analgesics may be needed. Referral to a podiatrist for callus debridement can be helpful. ${ }^{76}$

\section{Diarrhea}

Diarrhea is a common AE in patients on cabozantinib. Although diarrhea related to MTC may improve with MKI therapy, it may also worsen because of the MKI itself. Therefore, it is important that any diarrhea be treated prior to starting an MKI. Supportive measures include avoiding dietary triggers and adding a probiotic. Loperamide may also be started. If maximal doses of loperamide cannot control the diarrhea, patients can alternate doses of loperamide with diphenoxylate/atropine. For those whose symptoms are not controlled with this regimen, tincture of opium is often helpful. In more severe cases, other potential options include oral budesonide or parenteral octreotide. However, these two agents have not been evaluated in the context of MKIs. Monitoring for electrolyte abnormalities is necessary in patients with severe diarrhea. ${ }^{76}$

\section{Weight loss}

Weight loss in patients taking cabozantinib for advanced thyroid cancer has been described by Kwatampora et al. ${ }^{79}$ MKI-associated weight loss can be difficult to manage. The first consideration is whether another $\mathrm{AE}$ is contributing to weight loss. Diarrhea should be treated as detailed in the "Diarrhea" section. Patients should be assessed for nausea, vomiting, or stomatitis. MKI-associated dysgeusia may contribute to weight loss by decreasing dietary intake; there is no known effective treatment for dysgeusia. For some patients, consultation with a dietitian, and possibly recommendations for nutritional supplements, can be helpful. Appetite stimulants can also be considered.

\section{Salvage therapy}

It is believed patients on MKIs develop drug resistance through several mechanisms, including induction of alternative
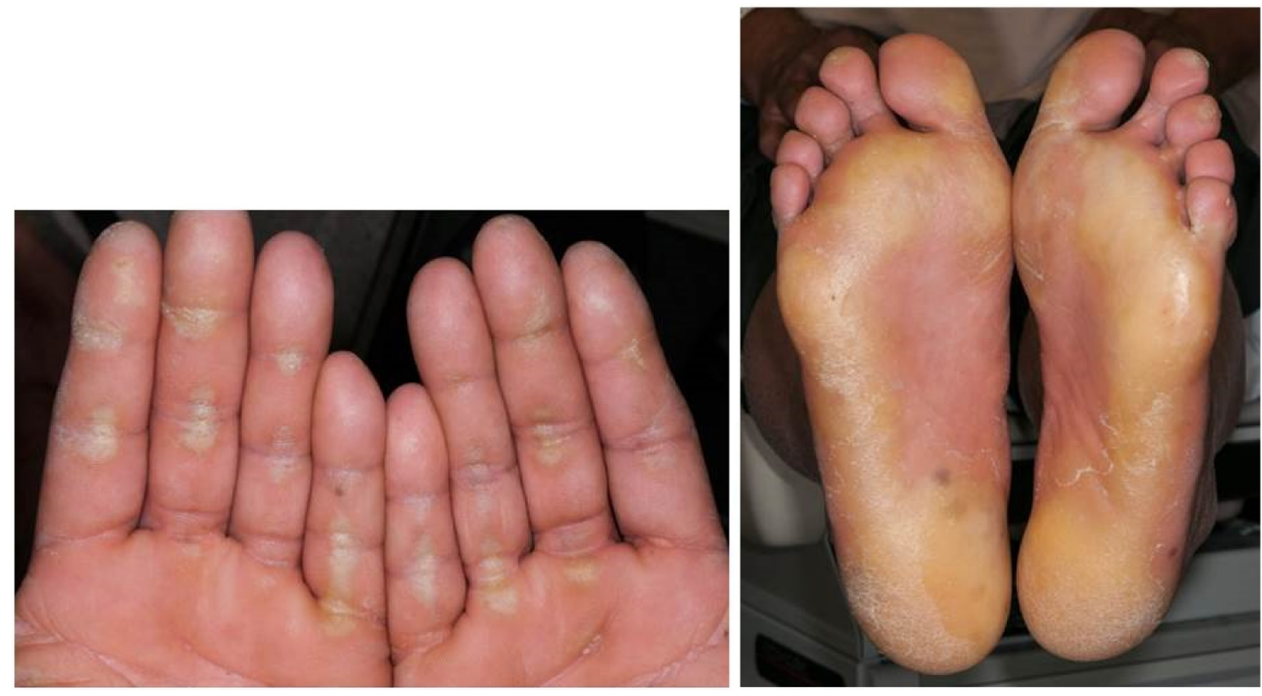

Figure 6 Hand-foot skin reaction

Note: Erythema, hyperkeratosis, and callus formation at sites of friction. 
signaling pathways which bypass the drug targets. ${ }^{80}$ In patients with MTC who have progression on an MKI, it is reasonable to change to a different MKI if the patient remains a candidate for further systemic therapy. Our group has presented data showing that a radiologic response is possible with a change to a different MKI following progression on an antiangiogenic MKI. However, the response to the subsequent MKI tended to be of shorter duration. ${ }^{81}$ Dadu et a ${ }^{82}$ retrospectively examined the response to other MKIs following failure of first-line sorafenib in DTC. They identified an improvement in median OS for those who received salvage when compared with those who did not (58 vs 28 months). ${ }^{82}$ Results of a Phase II study that looked specifically at cabozantinib in patients whose DTC progressed on antiangiogenic MKI therapy will be reported soon (NCT01811212). ${ }^{53}$

\section{Summary}

Cabozantinib is a potent MKI that has been proven effective in patients with progressive MTC and is currently being studied in DTC as well as other malignancies. Although there has been a demonstrated prolongation of PFS in patients with MTC, a difference in OS has not yet been shown. Advancements in the understanding of the molecular alterations underlying thyroid cancer coupled with the identification of targeted therapies have led to a change in the therapeutic landscape for patients with advanced thyroid cancer. For many clinicians, this change is accompanied by a need for further education and experience in selecting appropriate candidates with thyroid cancer for treatment with MKIs. The first challenge in using these agents is determining when initiating an MKI is the proper course of action. In general, MKIs should be reserved for patients with limited alternative options for symptomatic disease, disease threatening vital structures, or rapidly progressive disease. Since these agents are not curative, have no proven survival benefit, and are employed as chronic therapies, the decision to start MKI therapy must be based upon a careful risk/benefit analysis relevant to the patient's priorities and goals of care.

Optimal management of AEs is crucial to maintaining patient quality of life while on an MKI. Because some AEs are serious and can result in morbidity and even mortality, patients receiving an MKI should be closely monitored, with aggressive management of AEs.

\section{Acknowledgments}

We thank Kathryn Hale for her editorial services. This study was supported in part by the US National Cancer Institute through The University of Texas MD Anderson Cancer Center Support Grant (CA16672).

\section{Disclosure}

MEC has received grant funding from Eisai, Exelixis, and Roche. MEC has received consultant fees from AstraZeneca, Exelixis, Eisai, and Bayer. The authors report no other conflicts of interest in this work.

\section{References}

1. COMETRIQ ${ }^{\mathrm{TM}}$ [package insert]. South San Francisco, CA: Exelixis, Inc.; 2012. Available from: http://www.cometriq.com/downloads/Cometriq_ Full_Prescribing_Information.pdf. Accessed March 29, 2015.

2. National Cancer Institute at the National Institutes of Health. Cancer of the Thyroid - SEER Stat Fact Sheets. Bethesda, MD: National Cancer Institute at the National Institutes of Health. Available from: http://seer. cancer.gov/statfacts/html/thyro.html. Accessed March 27, 2015.

3. Ruegemer JJ, Hay ID, Bergstralh EJ, Ryan JJ, Offord KP, Gorman CA. Distant metastases in differentiated thyroid carcinoma: a multivariate analysis of prognostic variables. J Clin Endocrinol Metab. 1988;67(3): 501-508.

4. Besic N, Gazic B. Sites of metastases of anaplastic thyroid carcinoma: autopsy findings in 45 cases from a single institution. Thyroid. 2013; 23(6):709-713.

5. Aschebrook-Kilfoy B, Ward MH, Sabra MM, Devesa SS. Thyroid cancer incidence patterns in the United States by histologic type, 1992-2006. Thyroid. 2011;21(2):125-134.

6. Krampitz GW, Norton JA. RET gene mutations (genotype and phenotype) of multiple endocrine neoplasia type 2 and familial medullary thyroid carcinoma. Cancer. 2014;120(13):1920-1931.

7. Moura MM, Cavaco BM, Pinto AE, Leite V. High prevalence of RAS mutations in RET-negative sporadic medullary thyroid carcinomas. J Clin Endocrinol Metab. 2011;96(5):E863-E868.

8. Capp C, Wajner SM, Siqueira DR, Brasil BA, Meurer L, Maia AL. Increased expression of vascular endothelial growth factor and its receptors, VEGFR-1 and VEGFR-2, in medullary thyroid carcinoma. Thyroid. 2010;20(8):863-871.

9. The Cancer Genome Atlas Research Network. Integrated genomic characterization of papillary thyroid carcinoma. Cell. 2014;159(3):676-690.

10. Nikiforova MN, Nikiforov YE. Molecular genetics of thyroid cancer: implications for diagnosis, treatment and prognosis. Expert Rev Mol Diagn. 2008;8(1):83-95.

11. Abdel-Rahman O. Targeting vascular endothelial growth factor (VEGF) pathway in iodine-refractory differentiated thyroid carcinoma (DTC): from bench to bedside. Crit Rev Oncol Hematol. 2015; 94(1):45-54.

12. de Araujo-Filho VJ, Alves VA, de Castro IV, et al. Vascular endothelial growth factor expression in invasive papillary thyroid carcinoma. Thyroid. 2009;19(11):1233-1237.

13. Ricarte-Filho JC, Ryder M, Chitale DA, et al. Mutational profile of advanced primary and metastatic radioactive iodine-refractory thyroid cancers reveals distinct pathogenetic roles for BRAF, PIK3CA, and AKT1. Cancer Res. 2009;69(11):4885-4893.

14. Schwartz DL, Rana V, Shaw S, et al. Postoperative radiotherapy for advanced medullary thyroid cancer-local disease control in the modern era. Head Neck. 2008;30(7):883-888.

15. Lindsey SC, Ganly I, Palmer F, Tuttle RM. Response to initial therapy predicts clinical outcomes in medullary thyroid cancer. Thyroid. 2015;25(2):242-249.

16. Wells SA Jr, Asa SL, Dralle H, et al. Revised american thyroid association guidelines for the management of medullary thyroid carcinoma. Thyroid. 2015;25(6):567-610. 
17. Yeh MW, Bauer AJ, Bernet VA, et al. American thyroid association statement on preoperative imaging for thyroid cancer surgery. Thyroid. 2015;25(1):3-14.

18. Tuttle RM, Haddad RI, Ball DW, et al. Thyroid carcinoma, version 2.2014. J Natl Compr Canc Netw. 2014;12(12):1671-1680.

19. Cooper DS, Doherty GM, Haugen BR, et al. Revised american thyroid association management guidelines for patients with thyroid nodules and differentiated thyroid cancer. Thyroid. 2009;19(11):1167-1214.

20. Brignardello E, Palestini N, Felicetti F, et al. Early surgery and survival of patients with anaplastic thyroid carcinoma: analysis of a case series referred to a single institution between 1999 and 2012. Thyroid. 2014; 24(11):1600-1606.

21. Mohebati A, Dilorenzo M, Palmer F, et al. Anaplastic thyroid carcinoma: a 25-year single-institution experience. Ann Surg Oncol. 2014;21(5):1665-1670.

22. Smallridge RC, Ain KB, Asa SL, et al. American thyroid association guidelines for management of patients with anaplastic thyroid cancer. Thyroid. 2012;22(11):1104-1139.

23. Haymart MR, Banerjee M, Yin H, Worden F, Griggs JJ. Marginal treatment benefit in anaplastic thyroid cancer. Cancer. 2013;119(17):3133-3139.

24. Durante C, Haddy N, Baudin E, et al. Long-term outcome of 444 patients with distant metastases from papillary and follicular thyroid carcinoma: benefits and limits of radioiodine therapy. J Clin Endocrinol Metab. 2006;91(8):2892-2899.

25. Orita Y, Sugitani I, Toda K, Manabe J, Fujimoto Y. Zoledronic acid in the treatment of bone metastases from differentiated thyroid carcinoma. Thyroid. 2011;21(1):31-35.

26. Gherardi E, Birchmeier W, Birchmeier C, Vande Woude G. Targeting MET in cancer: rationale and progress. Nat Rev Cancer. 2012;12(2): 89-103.

27. Aftab DT, McDonald DM. MET and VEGF: synergistic targets in castration-resistant prostate cancer. Clin Transl Oncol. 2011;13(10): 703-709.

28. Shojaei F, Lee JH, Simmons BH, et al. HGF/c-Met acts as an alternative angiogenic pathway in sunitinib-resistant tumors. Cancer Res. 2010;70(24):10090-10100.

29. Yakes FM, Chen J, Tan J, et al. Cabozantinib (XL184), a novel MET and VEGFR2 inhibitor, simultaneously suppresses metastasis, angiogenesis, and tumor growth. Mol Cancer Ther. 2011;10(12):2298-2308.

30. Tohyama O, Matsui J, Kodama K, et al. Antitumor activity of lenvatinib (e7080): an angiogenesis inhibitor that targets multiple receptor tyrosine kinases in preclinical human thyroid cancer models. J Thyroid Res. 2014;2014:638747.

31. Kumar R, Knick VB, Rudolph SK, et al. Pharmacokineticpharmacodynamic correlation from mouse to human with pazopanib, a multikinase angiogenesis inhibitor with potent antitumor and antiangiogenic activity. Mol Cancer Ther. 2007;6(7):2012-2021.

32. Wilhelm SM, Carter C, Tang L, et al. BAY 43-9006 exhibits broad spectrum oral antitumor activity and targets the RAF/MEK/ERK pathway and receptor tyrosine kinases involved in tumor progression and angiogenesis. Cancer Res. 2004;64(19):7099-7109.

33. Plaza-Menacho I, Mologni L, Sala E, et al. Sorafenib functions to potently suppress RET tyrosine kinase activity by direct enzymatic inhibition and promoting RET lysosomal degradation independent of proteasomal targeting. J Biol Chem. 2007;282(40):29230-29240.

34. Carlomagno F, Anaganti S, Guida T, et al. BAY 43-9006 inhibition of oncogenic RET mutants. J Natl Cancer Inst. 2006;98(5):326-334.

35. Wilhelm S, Carter C, Lynch M, et al. Discovery and development of sorafenib: a multikinase inhibitor for treating cancer. Nat Rev Drug Discov. 2006;5(10):835-844.

36. Faivre S, Demetri G, Sargent W, Raymond E. Molecular basis for sunitinib efficacy and future clinical development. Nat Rev Drug Discov. 2007;6(9):734-745.

37. Kim DW, Jo YS, Jung HS, et al. An orally administered multitarget tyrosine kinase inhibitor, SU11248, is a novel potent inhibitor of thyroid oncogenic RET/papillary thyroid cancer kinases. J Clin Endocrinol Metab. 2006;91(10):4070-4076.
38. Abrams TJ, Lee LB, Murray LJ, Pryer NK, Cherrington JM. SU11248 inhibits KIT and platelet-derived growth factor receptor beta in preclinical models of human small cell lung cancer. Mol Cancer Ther. 2003;2(5):471-478.

39. Wedge SR, Ogilvie DJ, Dukes M, et al. ZD6474 inhibits vascular endothelial growth factor signaling, angiogenesis, and tumor growth following oral administration. Cancer Res. 2002;62(16):4645-4655.

40. Carlomagno F, Vitagliano D, Guida T, et al. ZD6474, an orally available inhibitor of KDR tyrosine kinase activity, efficiently blocks oncogenic RET kinases. Cancer Res. 2002;62(24):7284-7290.

41. Kurzrock R, Sherman SI, Ball DW, et al. Activity of XL184 (Cabozantinib), an oral tyrosine kinase inhibitor, in patients with medullary thyroid cancer. J Clin Oncol. 2011;29(19):2660-2666.

42. Schlumberger M, Elisei R, Muller S, et al. Final overall survival analysis of EXAM, an international, double-blind, randomized, placebocontrolled phase Ill trial of cabozantinib (Cabo) in medullary thyroid carcinoma (MTC) patients with documented RECIST progression at baseline. Presented at: The 2015 Annual Meeting of the American Society of Clinical Oncology, Chicago, IL; 2015. Abstract 6012.

43. Elisei R, Schlumberger MJ, Muller SP, et al. Cabozantinib in progressive medullary thyroid cancer. J Clin Oncol. 2013;31(29):3639-3646.

44. US Food and Drug Administration. Approved Drugs: Cabozantinib; 2012. Available from: http://www.fda.gov/Drugs/InformationOnDrugs/ ApprovedDrugs/ucm330213.htm. Accessed March 29, 2015.

45. US Food and Drug Administration. FDA approves new treatment for rare form of thyroid cancer [Press Announcements]. Silver Spring, MD: US Food and Drug Administration; [April 6, 2011]. Available from: http://www.fda.gov/NewsEvents/Newsroom/PressAnnouncements/ ucm250168.htm. Accessed April 29, 2015.

46. Wells SA Jr, Robinson BG, Gagel RF, et al. Vandetanib in patients with locally advanced or metastatic medullary thyroid cancer: a randomized, double-blind phase III trial. J Clin Oncol. 2012;30(2):134-141.

47. US Food and Drug Administration. FDA approves Nexavar to treat type of thyroid cancer [Press Announcements]. Silver Spring, MD: US Food and Drug Administration; [November 22, 2013]. Available from: http:/www.fda.gov/NewsEvents/Newsroom/PressAnnouncements/ ucm376443.htm. Accessed April 5, 2015.

48. Brose MS, Nutting CM, Jarzab B, et al. Sorafenib in radioactive iodinerefractory, locally advanced or metastatic differentiated thyroid cancer: a randomised, double-blind, phase 3 trial. Lancet. 2014;384(9940):319-328.

49. US Food and Drug Administration. FDA approves Lenvima for a type of thyroid cancer [Press Announcements]. Silver Spring, MD: US Food and Drug Administration; [February 13, 2015]. Available from: http://www.fda.gov/NewsEvents/Newsroom/PressAnnouncements/ ucm434288.htm. Accessed April 5, 2015.

50. Schlumberger M, Tahara M, Wirth LJ, et al. Lenvatinib versus placebo in radioiodine-refractory thyroid cancer. $N$ Engl J Med. 2015;372(7): 621-630.

51. Nguyen L, Holland J, Miles D, et al. Pharmacokinetic (PK) drug interaction studies of cabozantinib: effect of CYP3A4 inducer rifampin and inhibitor ketoconazole on cabozantinib plasma PK, and effect of cabozantinib on CYP2C8 probe substrate rosiglitazone plasma PK. J Clin Pharmacol. Epub April 8, 2015.

52. Abramson Cancer Center of the University of Pennsylvania. A phase II trial of cabozantinib for the treatment of radioiodine (RAI)-refractory differentiated thyroid carcinoma (DTC) in the first-line setting. Available from: https:/clinicaltrials.gov/show/NCT02041260. NLM identifier: 02041260. Accessed April 5, 2015.

53. National Cancer Institute. Cabozantinib-s-malate in treating patients with refractory thyroid cancer. Available from: https://clinicaltrials.gov/show/ NCT01811212. NLM identifier: 01811212. Accessed April 5, 2015.

54. Bible KC, Suman VJ, Menefee ME, et al. A multiinstitutional phase 2 trial of pazopanib monotherapy in advanced anaplastic thyroid cancer. J Clin Endocrinol Metab. 2012;97(9):3179-3184.

55. Savvides P, Nagaiah G, Lavertu P, et al. Phase II trial of sorafenib in patients with advanced anaplastic carcinoma of the thyroid. Thyroid. 2013;23(5):600-604. 
56. Sosa JA, Elisei R, Jarzab B, et al. Randomized safety and efficacy study of fosbretabulin with paclitaxel/carboplatin against anaplastic thyroid carcinoma. Thyroid. 2014;24(2):232-240.

57. Takahashi S, Tahara M, Kiyota N, et al. Phase II study of lenvatinib, a multitargeted tyrosine kinase inhibitor, in patients with all histologic subtypes of advanced thyroid cancer (differentiated, medullary, and anaplastic). Poster presented at: European Society for Medical Oncology 2014 Congress, September 26-30, 2014, Madrid, Spain. Abstract \#995PD. Available from: http://oncologypro.esmo.org/Meeting-Resources/ ESMO-2014/Head-and-Neck-Cancer/Phase-II-study-of-lenvatinibLEN-a-multi-targeted-tyrosine-kinase-inhibitor-in-patients-pts-with-allhistologic-subtypes-of-advanced-thyroid-cancer-differentiated-medullar y-and-anaplastic. Accessed July 11, 2015.

58. Eisai Co, Ltd. Eisai receives approval in Japan for anticancer agent Lenvima (lenvatinib mesylate) as treatment for unresectable thyroid cancer; 2015. Available from: http://www.eisai.com/news/news201520. html. Accessed April 8, 2015.

59. GlaxoSmithKline. Efficacy and safety of the combination therapy of dabrafenib and trametinib in subjects with BRAF V600E-mutated rare cancers. Available from: https://clinicaltrials.gov/show/NCT02034110. NLM identifier: NCT02034110. Accessed April 13, 2015.

60. National Cancer Institute. Intensity-modulated radiation therapy and paclitaxel with or without pazopanib hydrochloride in treating patients with anaplastic thyroid cancer. Available from: https://clinicaltrials. gov/show/NCT01236547. NLM identifier: NCT01236547. Accessed March 29, 2015.

61. US National Institutes of Health. Home - ClinicalTrials.gov. Available from: https://clinicaltrials.gov/. Accessed April 12, 2015.

62. Fagin JA, Tuttle RM, Pfister DG. Harvesting the low-hanging fruit: kinase inhibitors for therapy of advanced medullary and nonmedullary thyroid cancer. J Clin Endocrinol Metab. 2010;95(6):2621-2624.

63. Eisenhauer EA, Therasse P, Bogaerts J, et al. New response evaluation criteria in solid tumours: revised RECIST guideline (version 1.1). Eur J Cancer. 2009;45(2):228-247.

64. Therasse P, Arbuck SG, Eisenhauer EA, et al. New guidelines to evaluate the response to treatment in solid tumors. European Organization for Research and Treatment of Cancer, National Cancer Institute of the United States, National Cancer Institute of Canada. J Natl Cancer Inst. 2000;92(3):205-216.

65. Oken MM, Creech RH, Tormey DC, et al. Toxicity and response criteria of the Eastern Cooperative Oncology Group. Am J Clin Oncol. 1982; 5(6):649-655.

66. Cabanillas ME, Hu MI, Jimenez C. Medullary thyroid cancer in the era of tyrosine kinase inhibitors: to treat or not to treat - and with which drug - those are the questions. J Clin Endocrinol Metab. 2014;99(12):4390-4396.

67. Blevins DP, Dadu R, Hu M, et al. Aerodigestive fistula formation as a rare side effect of antiangiogenic tyrosine kinase inhibitor therapy for thyroid cancer. Thyroid. 2014;24(5):918-922.

68. Cabanillas ME, Brose MS, Holland J, Ferguson KC, Sherman SI. A phase I study of cabozantinib (XL184) in patients with differentiated thyroid cancer. Thyroid. 2014;24(10):1508-1514.

69. Neri A, Lambert Y, Marrelli D, et al. Gastro-pleuro-pericardial fistula following combined radiation and chemotherapy for lung metastases from renal cell carcinoma: report of a case. Surg Today. 2013;43(12): $1457-1460$

Cancer Management and Research

\section{Publish your work in this journal}

Cancer Management and Research is an international, peer-reviewed open access journal focusing on cancer research and the optimal use of preventative and integrated treatment interventions to achieve improved outcomes, enhanced survival and quality of life for the cancer patient. The journal welcomes original research, clinical \& epidemiological
70. Smith MR, Sweeney CJ, Corn PG, et al. Cabozantinib in chemotherapypretreated metastatic castration-resistant prostate cancer: results of a phase II nonrandomized expansion study. J Clin Oncol. 2014;32(30): 3391-3399.

71. Marino R, Orlandi F, Arecco F, Gandolfo S, Pentenero M. Osteonecrosis of the jaw in a patient receiving cabozantinib. Aust Dent J. Epub December 4, 2014.

72. National Cancer Institute. Common Terminology Criteria for Adverse Events (CTCAE) Version 4.0; 2009. Available from: http://evs.nci.nih. gov/ftp1/CTCAE/CTCAE_4.03_2010-06-14_QuickReference_8.5x11. pdf. Accessed April 23, 2015.

73. Carhill AA, Cabanillas ME, Jimenez C, et al. The noninvestigational use of tyrosine kinase inhibitors in thyroid cancer: establishing a standard for patient safety and monitoring. J Clin Endocrinol Metab. 2013;98(1): 31-42.

74. Exelixis. A study of two different doses of cabozantinib (XL184) in progressive, metastatic medullary thyroid cancer (EXAMINER). Available from: https:/clinicaltrials.gov/show/NCT01896479. NLM Identifier: 01896479. Accessed April 5, 2015.

75. Bible KC, Ain KB, Rosenthal MS. Protein kinase inhibitor therapy in advanced thyroid cancer: ethical challenges and potential solutions. Int J Endocr Oncol. 2014;1(2):145-151.

76. Cabanillas ME, Hu MI, Jimenez C, Grubbs EG, Cote GJ. Treating medullary thyroid cancer in the age of targeted therapy. Int J Endocr Oncol. 2014;1(2):203-216.

77. Yavuz S, Apolo AB, Kummar S, et al. Cabozantinib-induced thyroid dysfunction: a review of two ongoing trials for metastatic bladder cancer and sarcoma. Thyroid. 2014;24(8):1223-1231.

78. Sherman S, Schlumberger M, Tahara M, et al. Relationship between thyroid-stimulating hormone levels and outcomes from the randomized, double-blind, phase 3 study of (E7080) lenvatinib in differentiated cancer of the thyroid (SELECT). Poster presented at: The 97th Annual Meeting of the Endocrine Society, San Diego, CA; 2015. Abstract THR-331.

79. Kwatampora L, Cabanillas M, Korivi B, Fogelman D, Dadu R, Busaidy N. Effect of cabozantinib on body composition in advanced thyroid cancer. Poster presented at: The 97th Annual Meeting of the Endocrine Society, San Diego, CA; 2015. Abstract \#THR-050.

80. Fallahi P, Mazzi V, Vita R, et al. New therapies for dedifferentiated papillary thyroid cancer. Int J Mol Sci. 2015;16(3):6153-6182.

81. Weitzman S, Peicher K, Dadu R, et al. Salvage therapy: when a tyrosine kinase inhibitor (TKI) fails in advanced medullary thyroid cancer (MTC). Poster presented at: The 97th Annual Meeting of the Endocrine Society, San Diego, CA; 2015. Abstract OR44-44.

82. Dadu R, Devine C, Hernandez M, et al. Role of salvage targeted therapy in differentiated thyroid cancer patients who failed first-line sorafenib. J Clin Endocrinol Metab. 2014;99(6):2086-2094.

83. Cabanillas ME, Hu MI, Jimenez C. Medullary thyroid cancer in the era of tyrosine kinase inhibitors: to treat or not to treat - and with which drug - those are the questions. J Clin Endocrinol Metab. 2014; 99(12):4394.

\section{Dovepress}

studies, reviews \& evaluations, guidelines, expert opinion \& commentary, case reports \& extended reports. The manuscript management system is completely online and includes a very quick and fair peerreview system, which is all easy to use. Visit http://www.dovepress.com/ testimonials.php to read real quotes from published authors. 